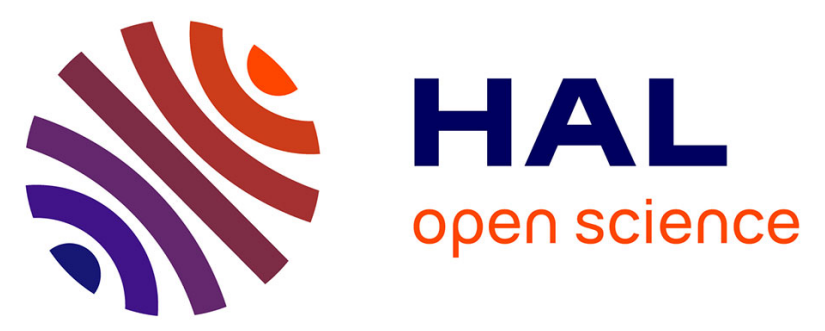

\title{
Transmission electron microscopy characterization of the dislocations and slip systems of the dense hydrous magnesium silicate superhydrous B
}

\author{
Alexandre Mussi, Patrick Cordier, Daniel Frost
}

\section{- To cite this version:}

Alexandre Mussi, Patrick Cordier, Daniel Frost. Transmission electron microscopy characterization of the dislocations and slip systems of the dense hydrous magnesium silicate superhydrous B. European Journal of Mineralogy, 2013, European Journal of Mineralogy, 25 (4), pp.561-568. 10.1127/0935$1221 / 2013 / 0025-2308$. hal-02185070

\section{HAL Id: hal-02185070 \\ https://hal.univ-lille.fr/hal-02185070}

Submitted on 17 Jul 2019

HAL is a multi-disciplinary open access archive for the deposit and dissemination of scientific research documents, whether they are published or not. The documents may come from teaching and research institutions in France or abroad, or from public or private research centers.
L'archive ouverte pluridisciplinaire HAL, est destinée au dépôt et à la diffusion de documents scientifiques de niveau recherche, publiés ou non, émanant des établissements d'enseignement et de recherche français ou étrangers, des laboratoires publics ou privés. 


\title{
Transmission electron microscopy characterization of the dislocations and slip systems of superhydrous B
}

\author{
Alexandre MUSSI ${ }^{*}$, Patrick CORDIER ${ }^{1,2}$ and Daniel J. FROST ${ }^{2}$ \\ 'Unité Matériaux et Transformations, UMR 8207 CNRS-Université Lille1, \\ F-59655 Villeneuve d'Ascq, France \\ ${ }^{2}$ Bayerisches Geoinstitut, Universität Bayreuth, Germany.
}

Cite as:

A. Mussi, P. Cordier \& D.J. Frost (2013) Transmission electron microscopy characterization of the dislocations and slip systems of superhydrous B. European Journal of Mineralogy, 25, 561-568, https://doi.org/10.1127/0935-1221/2013/0025-2308

\begin{abstract}
Superhydrous B (shy B), is a dense hydrous magnesium silicate (DHMS) which exhibits a large stability field in cold slab conditions. It was deformed at $20 \mathrm{GPa}$ and at temperatures $1000-1100^{\circ} \mathrm{C}$. The resulting dislocations have been characterized by transmission electron microscopy (TEM) with the weak beam dark field (WBDF) and the large angle convergent beam electron diffraction (LACBED) techniques. We emphasize the role of (010) plane in the plasticity of phase Shy B. We report that [100] and [001] glide in (010), and also climb of [100]. We also observe $\langle 101\rangle$ glide in (010) and $\{111\}$ planes under high stress conditions.
\end{abstract}

Keywords: DHMS, superhydrous B, TEM, LACBED, dislocations, glide plane, climb.

“Corresponding author: alexandre.mussi@univ-lille1.fr 


\section{Introduction}

The dynamics of the mantle is evidenced at the surface of the Earth by plate tectonics and associated phenomenons like volcanism, earthquakes and mountain building. Subduction zones are of utmost importance since they represent the cold downwelling boundary of convection and can be considered as the driving force for plate tectonic. Concerning the water budget of the mantle, the subduction zones play a key role since they are the place where water can be incorporated into the mantle through hydrous phases (Schmidt \& Poli, 1998). Water, or hydrogen, considerably modifies the mechanical properties of the mantle, reducing the solidus temperature of the mantle rocks. Furthermore, water or water-bearing phases may be responsible for intermediate and deep earthquakes by phase transitions (Meade \& Jeanloz, 1991; Yamasaki \& Seno, 2003; Komabayashi et al., 2004; Omori et al., 2004). For instance, antigorite destabilizes at a depth exceeding 200km (Ulmer \& Trommsdorff, 1995) and transforms into dense hydrous magnesium silicates (DHMS, see Ringwood \& Major (1967) for synthesis and characterization in the $\mathrm{Mg}_{2} \mathrm{SiO}_{4}-\mathrm{MgO}-\mathrm{H}_{2} \mathrm{O}$ system). Under cold slabs conditions, phase $A\left(\mathrm{Mg}_{7} \mathrm{Si}_{2} \mathrm{O}_{14} \mathrm{H}_{6}\right)$, is the first DHMS to form (Komabayashi \& Omori, 2006), followed by phase $\mathrm{E}\left(\mathrm{Mg}_{2.27} \mathrm{Si}_{1.26} \mathrm{O}_{2.4} \mathrm{H}_{6}\right)$, superhydrous $B$ (shy $B)\left(\mathrm{Mg}_{10} \mathrm{Si}_{3} \mathrm{O}_{18} \mathrm{H}_{4}\right)$ and then phase $\mathrm{D}\left(\mathrm{MgSi}_{2} \mathrm{O}_{2} \mathrm{H}_{6}\right)$ which is stable under lower mantle conditions.

Up to now, very few studies have been conducted on the rheology of hydrous phases under pressure and temperature conditions relevant for subduction. Hilairet et al. $(2007,2009)$ have established that the viscosity of antigorite is very low, which may enable silent earthquakes through large deformation accommodations. Furthermore, Amiguet et al. (2012) have shown that lizardite is also very weak (flow stresses between 20 and $200 \mathrm{MPa}$ ). This phase which deforms easily by basal glide and kinking, could have played a role in initiating subduction. Recently, we have performed, by transmission electron microscopy (TEM), a first study on the plastic deformation mechanisms of phase $\mathrm{A}$ at $11 \mathrm{GPa}, 700$ and $400{ }^{\circ} \mathrm{C}$ (Mussi et al., 2012). We have shown that phase $A$ deforms primarily by basal glide of $1 / 3\langle 2 \overline{1} \overline{1} 0\rangle$ dislocations, and by pyramidal glide of $1 / 3\langle 2 \overline{1} \overline{1} 3\rangle$ dislocations (Mussi et al., 2012).

In this study, we focus on the plastic deformation mechanisms of shy B. This phase is stable over a large domain (ca. $300 \mathrm{~km}$ in depths) which coincides 
approximately with the mantle transition zone (Komabayashi \& Omori, 2006). We have synthetized and deformed a specimen of shy B under cold slab $\mathrm{P}, \mathrm{T}$ conditions in the multianvil apparatus. The deformation microstructures have then been characterized by TEM to identify the dislocations and slip systems.

\section{Experimental details}

\section{Crystal structure}

Pacalo \& Parise (1992) have characterized an orthorhombic crystal structure (aPP $\approx 5.09 \AA$, bPP $\approx 13.97 \AA$ and $\mathrm{CPP} \approx 8.70 \AA$ ), with a Pnnm space group, for a shy $\mathrm{B}$ polycrystal of composition $\mathrm{Mg}_{10} \mathrm{Si}_{3} \mathrm{O}_{14}(\mathrm{OH}) 4$ synthesized at $1400{ }^{\circ} \mathrm{C}$ and $20 \mathrm{GPa}$. In this structure, double layers, which contain both magnesium in octahedral sites and silicon in tetrahedral sites (O-T layers), alternate along the $b$ axis with single layers (O layers) which contain both magnesium and silicon in octahedral sites (Pacalo et al., 1992). Hydrogen atoms are located between the O-T layers and are linked to the oxygen atoms associated with magnesium. However, Koch-Müller et al. (2005) proposed a lower symmetry space group (Pnn2) for a polycrystal synthesized at $1200^{\circ} \mathrm{C}$ and $22 \mathrm{GPa}$, with $\mathrm{aKM} \approx 5.11 \AA$, bKM $\approx 14.02 \AA$ and $\mathrm{CKM} \approx 8.73 \AA$, using the $(\mathrm{a}, \mathrm{b}$, c) $\Rightarrow(b, a,-c)$ rotation law as the structure setting.

\section{High pressure synthesis and deformation}

The sample of shy B used in this study was synthesized and deformed at the Bayerisches Geoinstitut in a Kawai multianvil apparatus. For synthesis, a mixture of high purity oxides ( $\mathrm{MgO}, \mathrm{SiO}_{2}$ quartz, brucite), was compressed under quasihydrostatic conditions, and annealed 3 hours at 20GPa and $1100^{\circ} \mathrm{C}$ (run S5128). Then, the resulting phase was recovered, end-polished and positioned in another high-pressure cell designed to induce deviatoric stresses (Cordier \& Rubie, 2001), at the same pressure and at temperatures $1000-1100^{\circ} \mathrm{C}$, during $30 \mathrm{~min}$ (run S5131).

\section{Transmission electron microscopy}

Two thin foils were ion milled down to electron transparency, at liquid nitrogen temperature (in a Gatan ${ }^{\circledR}$ DuoMill ${ }^{\mathrm{TM}}$ Model 600 ), to reduce ion damage since shy $\mathrm{B}$ is sensitive to ion irradiation. For the same reasons, TEM analyses were conducted at the university of Lille with a Philips ${ }^{\circledR}$ CM30 microscope operated at $300 \mathrm{kV}$ and associated with a Gatan ${ }^{\circledR}$ cold stage (liquid nitrogen temperature) in order to minimize electron damage. 
Precession electron diffraction (PED) has been used to set diffraction conditions appropriate for dislocation imaging and characterization. This technique strongly reduces multiple diffractions and leads to intensities of diffraction spots closely related to the structure factors (Vincent \& Midgley, 1994). Hence, it facilitates structure identification. PED is achieved with a "Spinning Star" precession module from the Nanomegas company.

The dislocation Burgers vector identifications are performed using the conventional invisibility criterion $\boldsymbol{g} \cdot \boldsymbol{b}=0$ with the weak-beam dark-field (WBDF) technique, the Ishida's thickness fringe method (Ishida et al., 1980; and Miyajima \& Walte, 2009) and the LACBED technique (Tanaka et al., 1980; Cherns \& Preston, 1986; Cherns \& Morniroli, 1994; and Morniroli, 2004). These last two methods are useful to characterize electron sensitive materials. Indeed, they give access to the $\boldsymbol{g} . \boldsymbol{b}$ product, considering the orientation and the number of thickness fringes terminating on the analyzed dislocation (Ishida's method), or considering the orientation and the number of Bragg line splittings on the investigated dislocation (LACBED technique). Consequently, only three diffraction conditions are necessary to index a dislocation. When the dislocation segment analyzed is long enough, a single LACBED pattern may be sufficient to gather these three diffraction conditions.

\section{Results}

The sample average grain size is $30 \pm 5 \mu \mathrm{m}$. In some grains, we have observed boundaries which are crystallographically controlled (figure 1). Further analyses of electron diffraction patterns performed with the PED technique suggests that both Pnnm and Pnn2 may coexist in our sample. Since these two phases exhibit only slight structural differences that are not likely to affect dislocation structure, we will, in a first approach ignore the influence of space group differences in our characterization. We further note that the absence of evidence between dislocations and boundaries is a further evidence that plasticity is not significantly affected by these structural details. Most grains contain dislocations. Seven grains have been investigated in details. In all these grains, the dislocation densities, obtained with the Ham method (1961), are approximately the same (around $2.10^{12} \mathrm{~m}^{-2}$ ). Abundant lowangle sub-grain boundaries have been observed (Figure 2). 

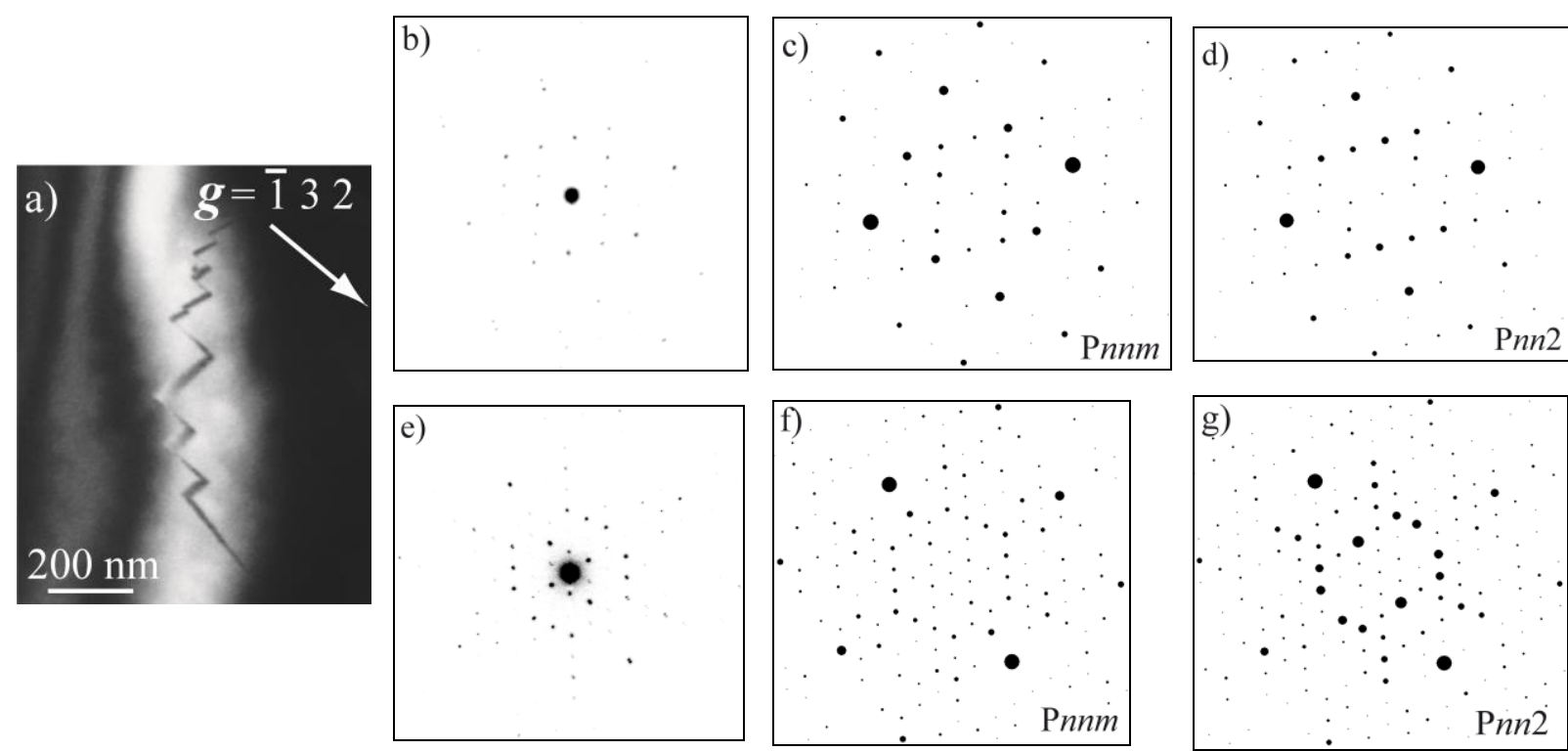

Figure 1: Antiphase boundary (APB), Pnnm and Pnn2 phase occurrences. (a) WBDF picture obtained along the $[11 \overline{1}]$ zone axis, with g: $\overline{1} 32$, showing a faceted $A P B$ in contrast; (b) PED experimental pattern of a grain along the [212] zone axis; (c) corresponding PED simulated pattern with the Pnnm space group, achieved with the Electron Diffraction software (Morniroli et al., 1994), with kinematic simulation, close to the experimental pattern; (d) corresponding PED simulated pattern with the Pnn2 space group, far from the experimental pattern; (e) PED experimental pattern of a grain along the [100] zone axis; (f) corresponding PED simulated pattern with the Pnnm space group, far from the experimental pattern; $(g)$ corresponding PED simulated pattern with the Pnn2 space group, close to the experimental pattern.

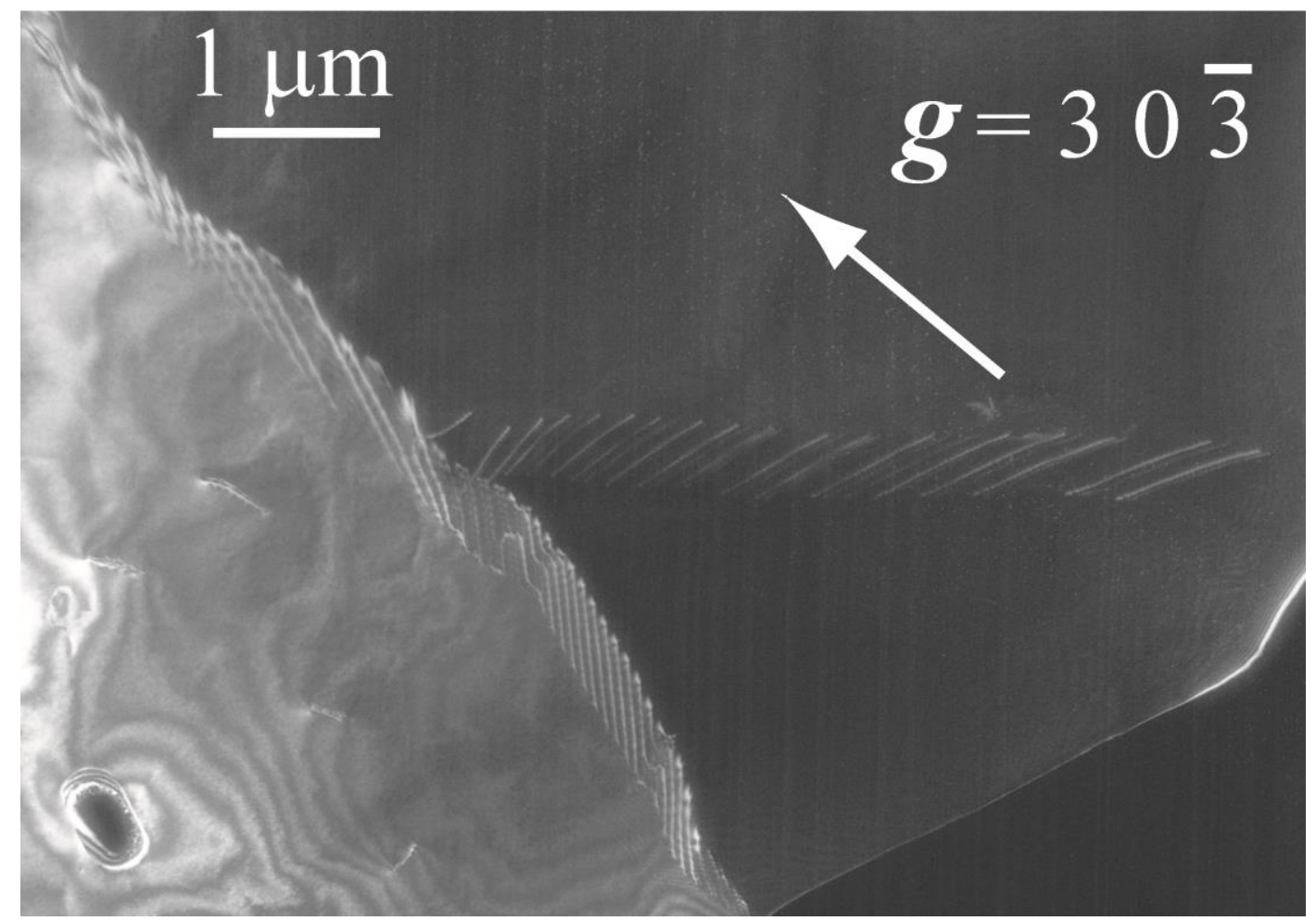

Figure 2: Micrographs of two sub-grains, viewed along the [111] zone axis, in WBDF condition, with g: $30 \overline{3}$. 


\section{Dislocation Burgers vectors}

Figures $3 a$ and $3 b$ show a grain containing four dislocation families labeled "1", "2", "3" and " 4 ". Figures $3 c$ is an enlargement of a dislocation from figure $3 a$ which is shown in figure $3 \mathrm{~d}$ with a different diffraction vector. From figure $3 \mathrm{c}$, imaged with the $\overline{3} 0 \overline{3}$ diffraction vector, the $\boldsymbol{g} \cdot \boldsymbol{b}$ product value of the considered dislocation is $n= \pm 3$, as determined from the Ishida's method (Ishida et al. 1980). This dislocation is out of contrast with g: $00 \overline{6}$, and exhibits $n= \pm 1$ with g: $\overline{1} 23$ (figure $3 \mathrm{~d}$ ). The Burgers vector of this dislocation is thus $\pm[100]$.
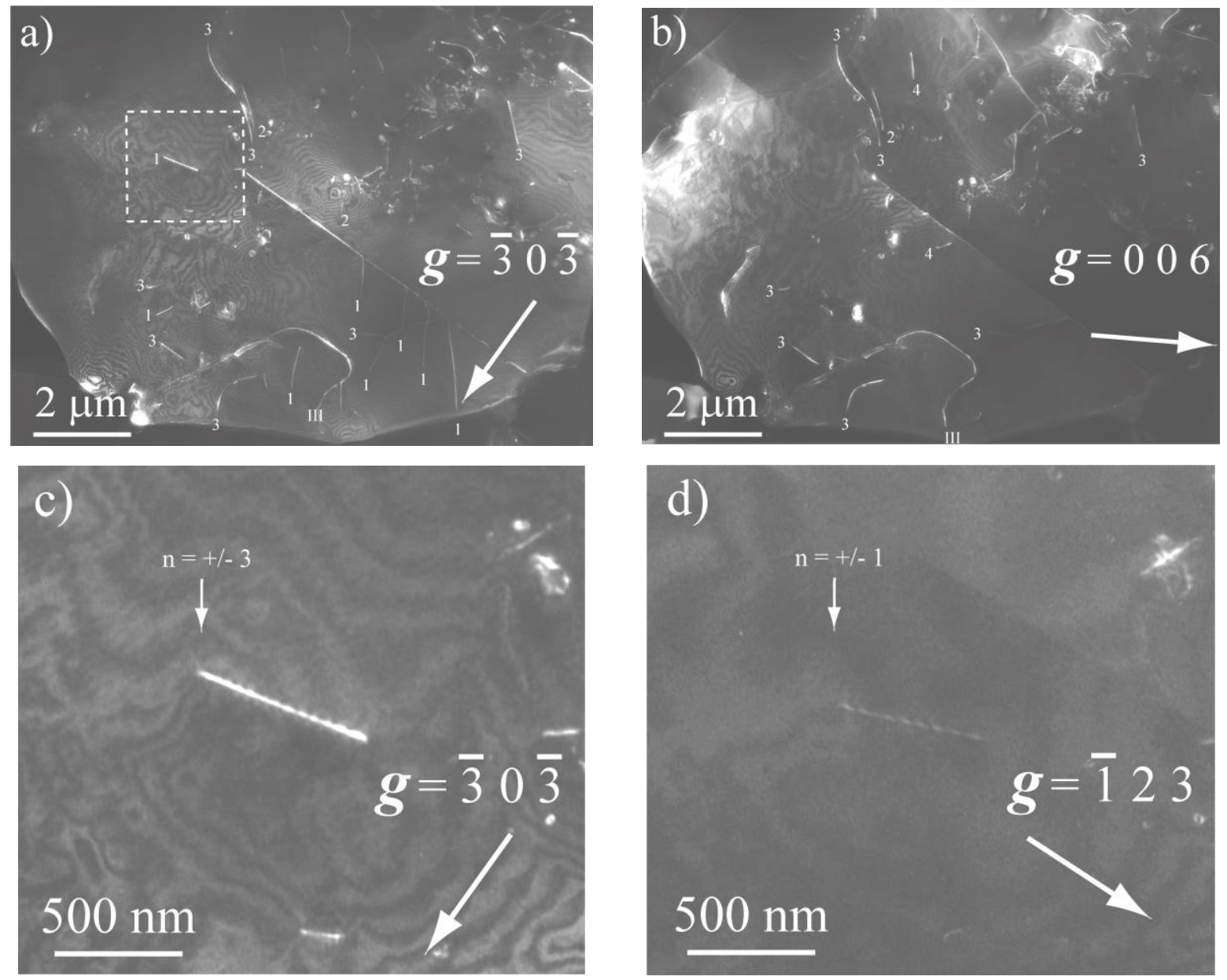

Figure 3: WBDF micrographs obtained along the [010] zone axis. (a) Diffraction vector $\boldsymbol{g}: \overline{3} 0 \overline{3}$, eight dislocations labeled "1", two dislocations labeled "2", and eight dislocations labeled "3" are in contrast, whose a long and curved dislocation labeled "III"; the dashed white lines rectangle designates the region magnified in (c) and (d); (b) diffraction vector $\mathbf{g :} 006$, dislocations "2", dislocations labeled "3", and two dislocations labeled "4" are in contrast; (c) zone magnified from (a) with $\boldsymbol{g}: \overline{3} 0 \overline{3}$ showing a dislocation with fringe contrast characteristic of $\boldsymbol{g} \cdot \boldsymbol{b}= \pm 3$; (d) same zone than (c) with $\boldsymbol{g}: \overline{1} 23$ showing a dislocation with fringe contrast characteristic of a $\boldsymbol{g} \cdot \boldsymbol{b}= \pm 1$. 
Figure 4a shows a grain containing three dislocation families. The dislocation (labeled "2") shown in figure $4 \mathrm{~b}$ exhibits a g.b product $n= \pm 6$ when imaged with $\mathrm{g}$ : 006 diffraction vector and is out of contrast with g: 600 (figure 4c). Furthermore, it appears, from other diffraction analyzes, that there is no $[0 v 0]$ component in the dislocation Burgers vector. Consequently, the Burgers vector of this dislocation is $\pm[001]$.
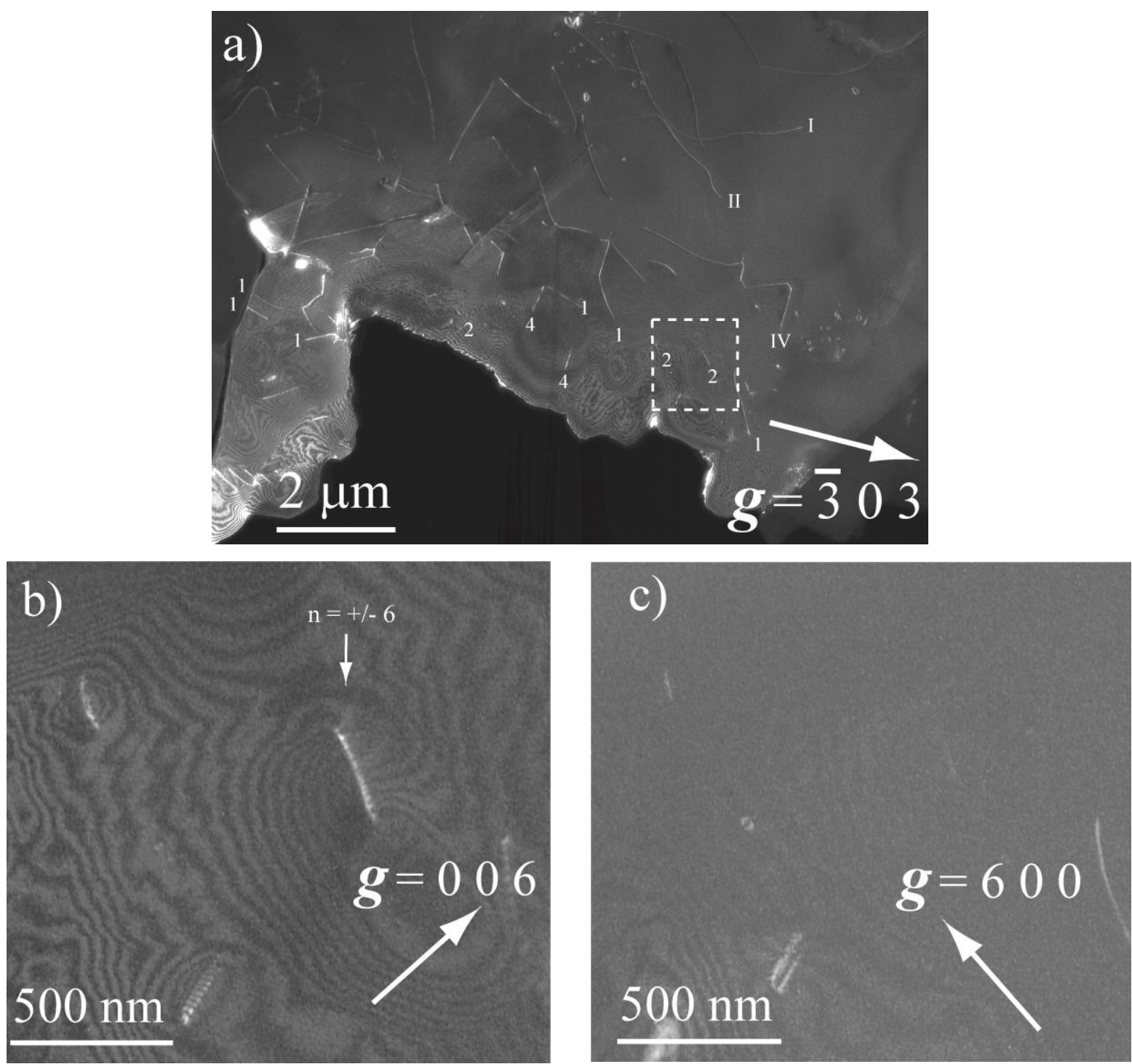

Figure 4: WBDF images achieved along the [010] zone axis. (a) Condition g: $\overline{3} 03$, seven dislocations labeled "1", whose a long and curved dislocation labeled "I", four dislocations labeled "2", whose a long and curved dislocation labeled "II", three dislocations labeled "4", whose a long and curved dislocation labeled "IV"; the dashed white straight lines rectangle designates the region zoomed in (b) and (c); (b) zone extracted from (a) with $\mathrm{g}$ : 006 showing a dislocation with fringe contrast characteristic of a g.b product of \pm 6 ; (c) same zone than (b) with $\mathbf{g}$ : 600 , the dislocation designated by an arrow in (b) is out of contrast. 
An example of a Burgers vector characterization, obtained exploiting the LACBED technique, is illustrated in figure 5. Three independent Bragg lines, indexed using the "Electron Diffraction" software from J.P. Morniroli et al. (1994), are superimposed over the studied dislocation. The Cherns and Preston rules (Cherns \& Preston, 1986), enable us to identify $n=-7$ with the $\overline{1} 66$ diffraction vector, $n=-2$ with $\overline{1} 71$, and $n=10$ with $1 \overline{5} \overline{9}$, looking at the splittings generated by the dislocation / Bragg line interactions. The resolution of the system of three equations gives the $[10 \overline{1}]$ Burgers vector. It can be noted, from the WBDF micrograph of the dislocation observed on figure 5 , that this dislocation is partially dissociated. The dissociation distance is too small to affect the LACBED patterns. The dissociation law should be symmetrical as various micrographs, obtained with three different diffraction conditions, reveal that both of the connected partial dislocations show the same contrast. We tentatively propose the following dissociation scheme: $[10 \overline{1}] \Leftrightarrow 1 / 2[10 \overline{1}]+1 / 2[10 \overline{1}]$.

Using the same methodology, all dislocation families labeled "1", "2", "3" and "4", observed on figures $3 a, 3 b$ and $4 a$, can be attributed the following Burgers vectors: $\pm[100], \pm[001], \pm[101]$ and $\pm[10 \overline{1}]$, respectively. It is worth noticing that all the $\langle 101\rangle$ dislocations, observed in these figures, are dissociated very probably with a symmetrical dissociation law: $\langle 101\rangle \Leftrightarrow 1 / 2\langle 101\rangle+1 / 2\langle 101\rangle$.

The diffraction vectors used for this characterization $(006,600,303,30 \overline{3}$, 0120 ...) have been selected for their high structure factor values (Table 1) which lead to a high contrast whenever the invisibility contrast is not satisfied.

During this study, 23 [100] dislocations, 12 [001] dislocations and $17\langle 101\rangle$ and $1 / 2\langle 101\rangle$ dislocations were found.

Table 1: Structure factors $F$ for several diffraction vectors $g$ calculated for $P n n 2$ and $P n n m$ respectively

\begin{tabular}{|c|c|c|c|c|c|c|c|}
\hline $\mathrm{g}$ & $\mathrm{F}$ & $\mathrm{g}$ & $\mathrm{F}$ & $\mathrm{g}$ & $\mathrm{F}$ & $\mathrm{g}$ & $\mathrm{F}$ \\
\hline 101 & $179 / 155$ & 002 & $2287 / 222$ & 200 & $442 / 169$ & 020 & $57 / 136$ \\
\hline 202 & $57 / 0$ & 004 & $259 / 606$ & 400 & $221 / 0$ & 040 & $0 / 2$ \\
\hline 303 & $4048 / 4606$ & 006 & $3783 / 4107$ & 600 & $651 / 771$ & 060 & $108 / 444$ \\
\hline 404 & $55 / 99$ & 008 & $254 / 31$ & 800 & $14 / 15$ & 080 & $56 / 70$ \\
\hline 505 & $21 / 4$ & 0010 & $10 / 42$ & 1000 & $19 / 1$ & 0100 & $85 / 36$ \\
\hline & & & & & & 0120 & $1095 / 1654$ \\
\hline & & & & & & 0140 & $0 / 12$ \\
\hline & & & & & & 0160 & $173 / 193$ \\
\hline
\end{tabular}




\section{$200 \mathrm{~nm}$}

\section{$g=00 \overline{6}$}

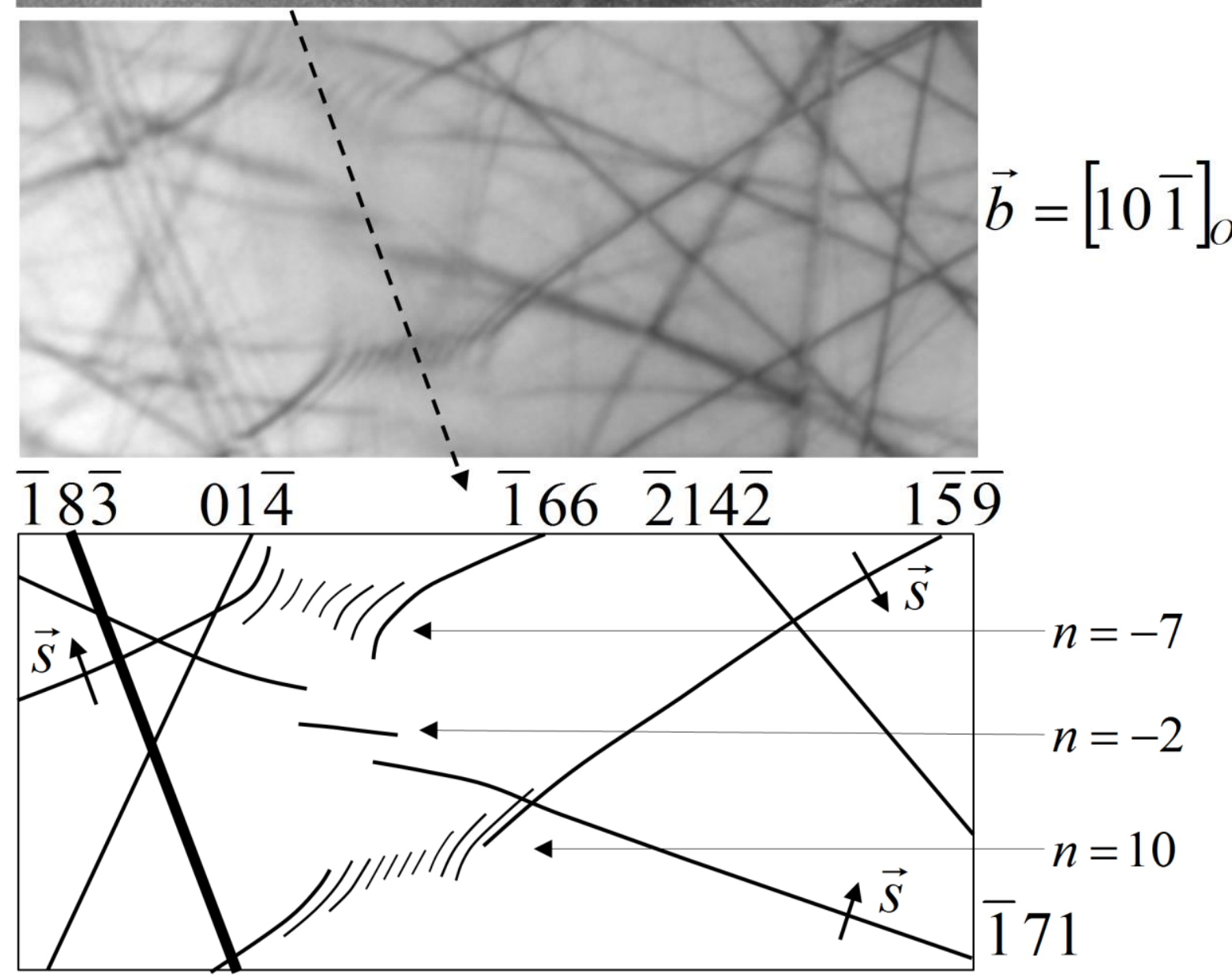

Figure 5: Indexation of a dislocation with the LACBED technique: (a) Micrograph of the studied dislocation viewed along the [100] zone axis, with g: $00 \overline{6}$; (b) experimental LACBED pattern where the black dashed arrow designates the shadow image of the dislocation (on the left of the pattern) and the orientation of the line vector; (c) kinematical simulation of the Bragg lines and kinematical simulation of the sign of the $s$ deviation parameter, achieved with the Electron Diffraction software (Morniroli et al., 1994), corresponding to the experimental pattern (the Bragg line splittings are indicated). 


\section{Slip planes and climb mechanisms}

Very long dislocations (several $\mu \mathrm{m}$ long), observed along two zone axes ([100] and [111]), are in contrast with the $\overline{3} 03$ and the $\overline{1} 4 \overline{3}$ diffraction vectors (figures $6 \mathrm{a}$ $6 b)$, with $n= \pm 3$ and $n= \pm 1$ respectively, and out of contrast with the $00 \overline{6}$ and the 0120 diffraction vectors (figures 6c-6d). Consequently, the Burgers vector of these dislocations is $\pm[100]$. As they are aligned along the [001] direction, they have an edge nature. This explains why a residual contrast is observed under conditions where $\boldsymbol{g} \cdot \boldsymbol{b}=0$ (figures $6 c-6 d$ ). This residual contrast enables us to note that, along the [100] zone axis, the plane which contains the considered dislocations is edge-on (dashed line on figure $6 \mathrm{~d}$ highlighting the trace of the (010) plane). Consequently, this dislocation belongs to the [100](010) slip system. Furthermore, a curved and long [100] dislocation (labeled "l") has been observed along the [010] zone axis in figure 4a. This confirms that [100] dislocations glide on the (010) plane. Most of the analyzed sub-grain boundaries are composed of [100] dislocations, as in figure 2 for example, which increases the proportion of [100] in relation to [001], $\langle 101\rangle$ and $1 / 2 \cdot\langle 101\rangle$ dislocations. Thus, [100] dislocations are also moving by climb, which is required to form equilibrated sub-grain boundaries.

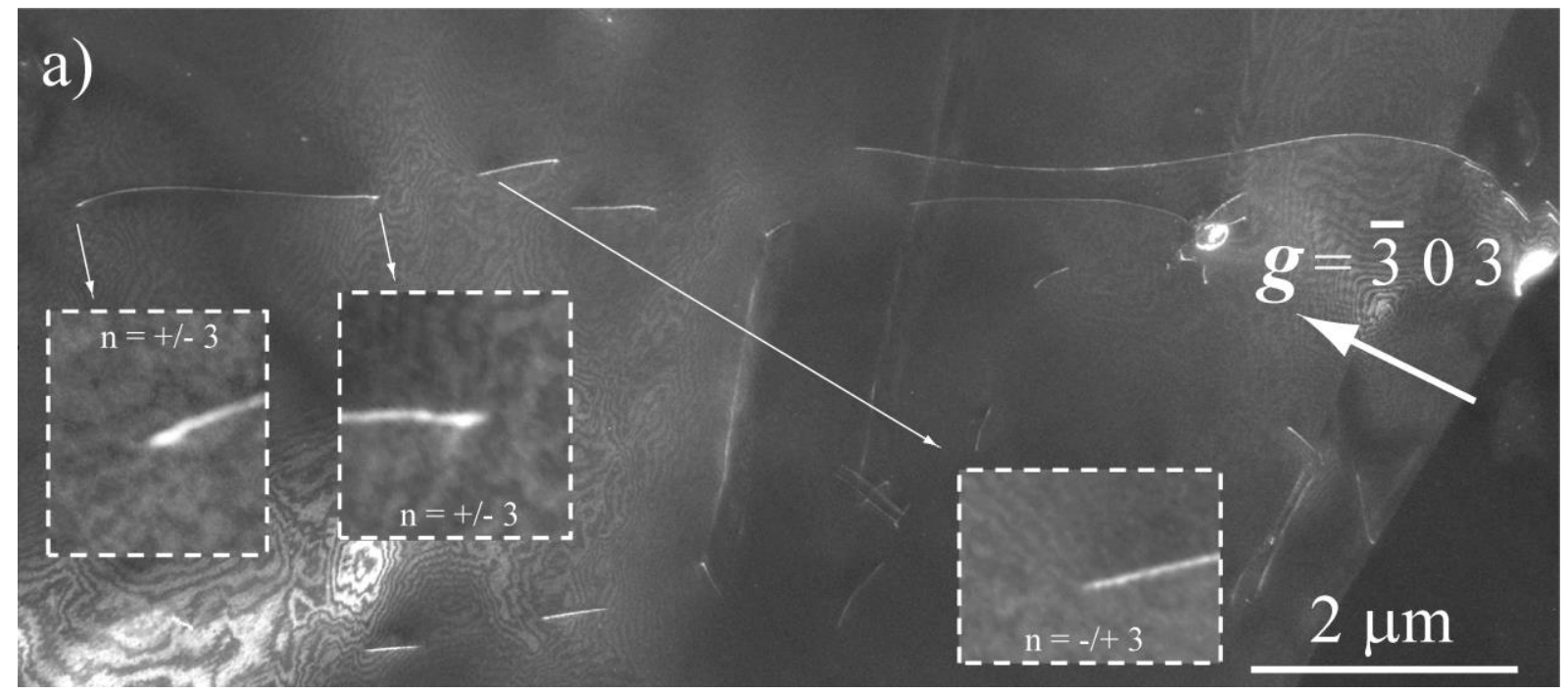



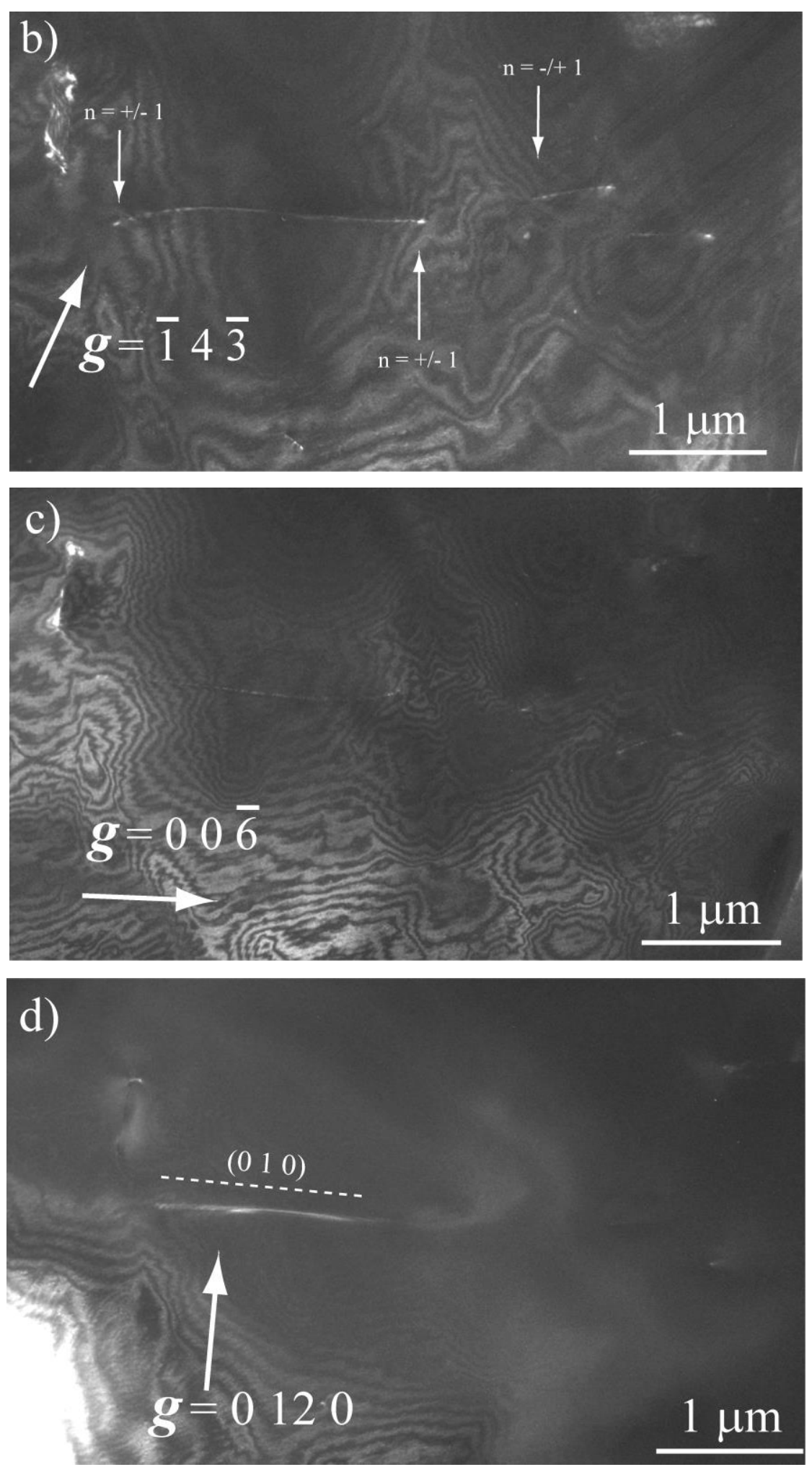

Figure 6: WBDF pictures achieved along the [100] zone axis. (a) Condition g: $\overline{3} 03$, showing long dislocations (the size of the longest one is $3.5 \mu \mathrm{m}$ ) with fringe contrast characteristic of a g.b product of \pm 3 (three zooms are done in order to see the fringe contrasts); (b) condition g: $\overline{1} 4 \overline{3}$ (left part of (a)), showing dislocations with fringe contrast characteristic of a g.b product of \pm 1 ; (c) same zone than (b) with g: $00 \overline{6}$, the long dislocations are out of contrast; (d) same zone than (b) with $\mathbf{g :} 0120$, the long dislocations have a residual contrast, which enables us to notice that the (010) plane is edge-on. 
From figures $3 \mathrm{a}$ and $4 \mathrm{a}$, long and curved dislocations, labeled "II", "III", and "IV", are observed along the [010] zone axis. As established previously, the Burgers vector of these dislocations are $\pm[001], \pm[101]$ and $\pm[10 \overline{1}]$ respectively. This suggests (010) as a likely glide plane for this dislocations, which leads to the slip systems: [001](010), [101](010), and [10 $\overline{1}](010)$.

Figures $7 \mathrm{a}$ and $7 \mathrm{~b}$ show several dissociated dislocations; a perfect one which begins to dissociate into two partial ones, labeled "single"; and dislocations dissociated into two, three and four partials, labeled "double", "triple" and "quadruple", respectively. They all exhibit the same line orientation: [0 $\overline{1} 1]$. We propose as a working hypothesis that they belong to the same dislocation family. From figure $7 \mathrm{c}$, the $\boldsymbol{g} . \boldsymbol{b}$ product value of the dislocation labeled "double" is found to be $n= \pm 3$ with the $00 \overline{6}$ diffraction vector (figure 7c). Furthermore, this dislocation is out of contrast with the $\overline{3} 0 \overline{3}$ diffraction vector (figure $7 \mathrm{~d}$ ), and the stacking fault is in contrast with the $\overline{1} 32$ diffraction vector (figure $7 \mathrm{a}$ ). This suggests that the Burgers vectors of each partial dislocation are $\pm 1 / 2[10 \overline{1}]$, as already suggested. Taking into account the line direction of this dislocation, $[0 \overline{1} 1]$, the glide plane is (111), and so the slip system is $[10 \overline{1}](111)$. Moreover, the studied dissociated dislocation belongs to the $(10 \overline{1})$ plane, as this plane is seen edge-on, in figure $7 \mathrm{~b}$. Consequently, this dislocation glide on the (111) plane and climb dissociates on the $(10 \overline{1})$ plane with a large dissociation width (approximately $130 \mathrm{~nm}$ ).
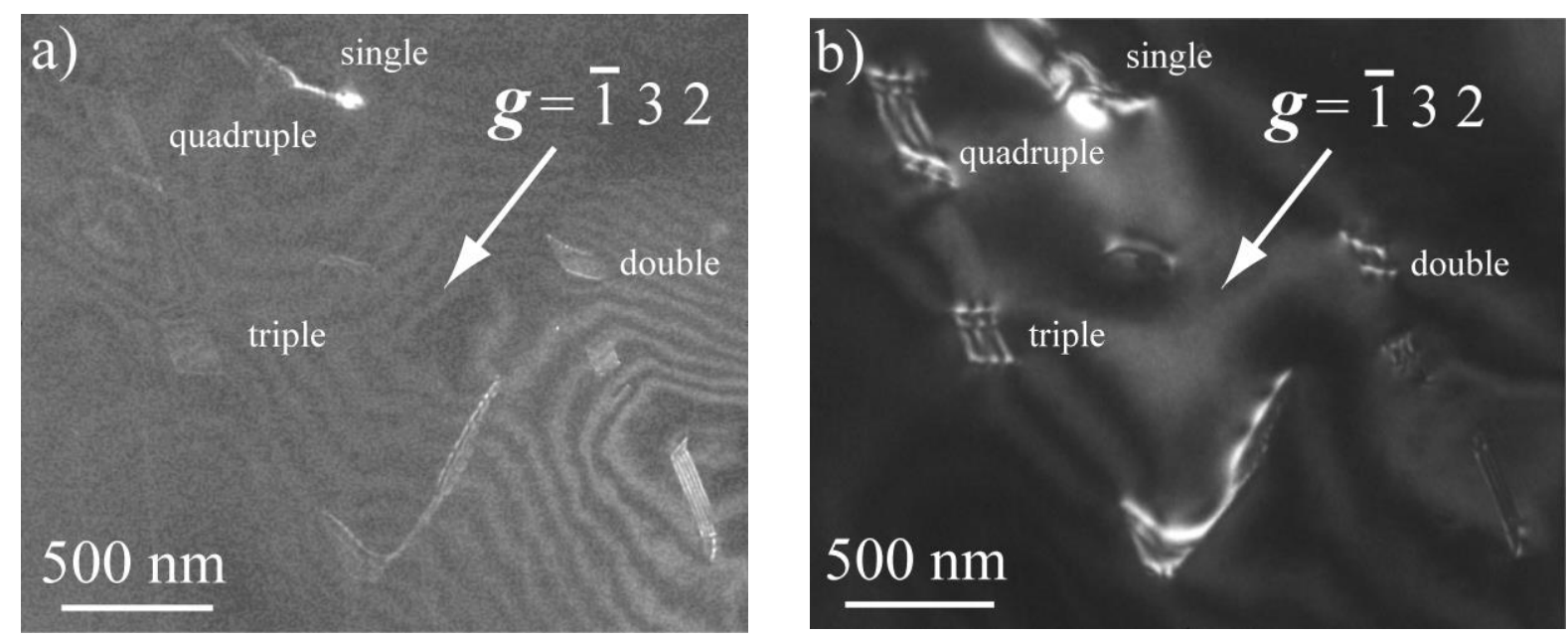

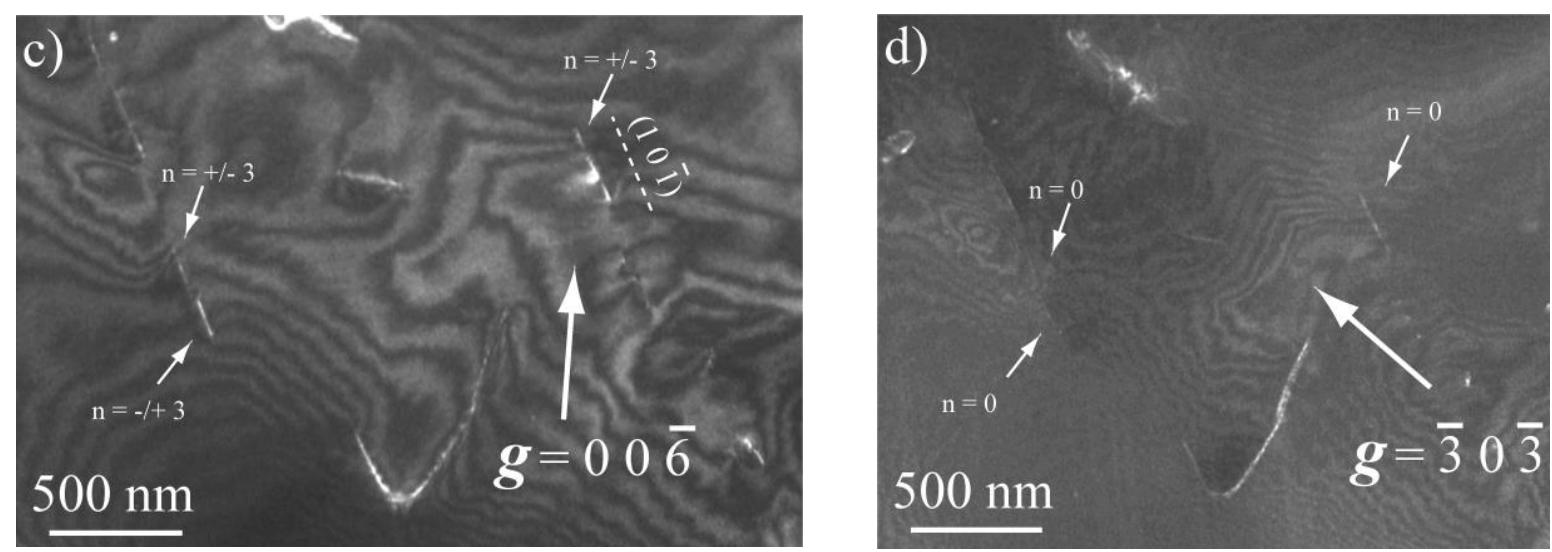

Figure 7: Micrographs in WBDF conditions. (a) Condition g: $\overline{1} 32$, along the $[11 \overline{1}]$ zone axis, dissociated dislocations labeled "single", "double", "triple" and "quadruple" are obtained with an high deviation parameter (the stacking faults are in contrast); (b) same zone, with the same condition, but with a smaller deviation parameter than in (a); (c) same zone, condition $\mathbf{g}: 00 \overline{6}$, along the [010] zone axis, showing three dislocations with fringe contrast characteristic of a g.b product of \pm 3 ; (d) same zone, condition $\mathrm{g}: \overline{3} 0 \overline{3}$, along the $[010]$ zone axis, the three dislocations designated by arrows in (c) are out of contrast.

\section{Discussion}

The elastic energy associated with a dislocation is proportional to $\mu b^{2}$ (per unit length of dislocation line), where $\mu$ is the shear modulus of the considered dislocation glide plane. From a simple energetic point of view, one expects that dislocations involve preferentially the shortest Burgers vector allowed by the crystal structure (in fact, the Bravais lattice). Indeed, in this study, we have shown the predominance of [100] dislocations $(b \approx 5.1 \AA)$, followed by [001] dislocations $(b \approx 8.7 \AA)$. Dislocations with the longest Burgers vector, $\langle 101\rangle(b \approx 10.1 \AA)$, are frequently dissociated into two $1 / 2\langle 101\rangle$ partial dislocations $(b \approx 5.0 \AA)$.

The occurrence of dislocations with Burgers vectors larger than $10 \AA$ raises the question of their stability. Frank (1951) has suggested that eventually, the elastic energy of a dislocation might exceed the surface energy leading to the formation of a hollow core. Nevertheless, such Burgers vectors have been recently discovered in anhydrous minerals like garnet and wadsleyite, and hydrous minerals as phase $A$. In phase $A$, we have reported $1 / 3\langle 11 \overline{2} 3\rangle$ dislocations with very large Burgers vectors

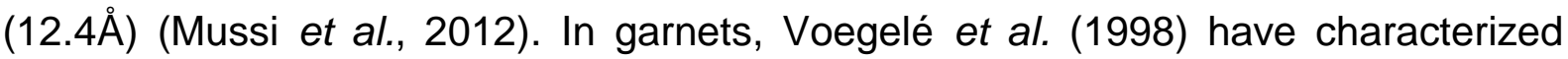
$1 / 2\langle 111\rangle(b \approx 10.0 \AA),\langle 100\rangle \quad(b \approx 11.5 \AA)$ and (less frequently) $\langle 110\rangle$ dislocations $(b \approx$ 
16.3Å). The latter is however restricted to the lowest temperatures where garnets approaches the brittle-ductile transition. In case of wadsleyite deformed experimentally, the observation of [010] dislocations (11.4 $\AA$ ) has been interpreted as the result of large stresses generated during cold compression of the sample in the multianvil apparatus (Thurel et al., 2003). It is likely that the observation in our specimen of $\langle 101\rangle$ dislocations with a large Burgers vector result from the same mechanism. Those dislocation are thus not regarded as the result of the deformation of shy $B$ at high-P, high-T.

The [100](010) and [001](010) slip systems have been identified in this study. Moreover, climb dissociation of $\langle 101\rangle$ perfect dislocations into $1 / 2\langle 101\rangle$ partial dislocations, in the $\{101\}$ planes, have been characterized in this specimen. The plastic anisotropy of shy $B$ is strongly constrained geometrical by the predominant role of the (010) plane in plastic glide. The observation of climb dissociation in some $\{101\}$ planes suggests that secondary glide or climb may take place in those planes. Glide in $\{111\}$ planes is observed, but only for dislocations with Burgers vectors of the $\langle 101\rangle$ type, generated at low temperatures under high stresses.

\section{Conclusion}

Our study suggests that under cold subduction conditions, plastic deformation of shy B could be accommodated by dislocations with plastic shear strongly localized in the (010) plane. Several shear directions along the [100], [001] (and possibly $\langle 101\rangle$ Burgers vectors under high stress) could be activated in this plane. This strongly anisotropic plastic behavior suggests that during subduction, shy $B$, if present, may develop strong crystal preferred orientation leading to markedly anisotropic elastic properties.

\section{Acknowledgements:}

The TEM national facility in Lille is supported by the CNRS (INSU) and the Conseil Régional du Nord - Pas de Calais, France. This study was supported by the ANR project SUBDEF grant $n^{\circ}$ ANR-08-BLAN-0192 to Bruno Reynard. 


\section{References}

Amiguet, E., Reynard, B., Caracas, R., Van de Moortèle, B., Hilairet, N., Wang, Y. (2012): Creep of phyllosilicates at the onset of plate tectonics. Earth Planet. Sci. Lett., 345-348, 142-150.

Bell, I.A., Wilson, C.J.L., McLaren, A.C., Etheridge, M.A. (1986): Kinks in mica: Role of dislocations and (001) cleavage. Tectonophysics, 127, 49-65.

Cherns, D. \& Morniroli, J.P. (1994): Analysis of partial and Stair-Rod dislocations by large angle convergent beam electron diffraction. Ultramicroscopy, 53, 2, 167180.

Cherns, D. \& Preston, A.R. (1986): Convergent-beam diffraction of crystal defects. In Proceedings Eleventh International Congress on Electron Microscopy, Kyoto, 721.

Christoffersen, R. \& Kronenberg, A.K. (1993): Dislocation interactions in experimentally deformed biotite. J. Struc. Geolg., 15, 1077-1095.

Cordier, P. \& Rubie, D.C. (2001): Plastic deformation of minerals under extreme pressure using a multianvil apparatus. Mater. Sci. Eng. A, 309-310, 38-43.

F. C. Frank, Acta Cryst. 4, 497 (1951).

Ham, R.K. (1961): The determination of dislocation densities in thin films. Phil. Mag., 6, 1183-1184.

Heggen, M., Houben, L., Feuerbacher, F. (2010): Plastic-deformation mechanism in complex solids, Nature Materials, 9, 332-336.

Hilairet, N. \& Reynard, B. (2009): Stability and dynamics of serpentinite layer in subduction zone. Tectonophysics, 465, 24-29.

Hilairet, N., Reynard, B., Wang, Y.B., Daniel, I., Merkel, S., Nishiyama, N., Petitgirard, S. (2007): High-pressure creep of serpentine, interseismic deformation, and initiation of subduction. Science, 318, 1910-1913.

Ishida, Y., Ishida, H., Kohra, K., Ichinose, H. (1980): Determination of the Burgers vector of a dislocation by weak-beam imaging in a HVEM. Phil. Mag. A, 42, 453-462.

Koch-Müller, M., Dera, P., Fei, Y., Hellwig, H., Liu, Z., Van Orman, J., Wirthe, R. (2005): Polymorphic phase transition in superhydrous phase B. Phys. Chem. Minerals, 32, 349-361. 
Komabayashi, T. \& Omori, S. (2006): Internally consistent thermodynamic data set for dense hydrous magnesium silicates up to $35 \mathrm{GPa}, 1600^{\circ} \mathrm{C}$ : implications for water circulation in the Earth's deep mantle. Phys. Earth Planet. Inter., 156, 89107.

Meade, C. \& Jeanloz, R. (1991): Deep-focus earthquakes and recycling of water into the earth's mantle. Science, 252, 68-72.

Metsue, A., Carrez, P., Denoual, C., Mainprice, D., Cordier, P. (2010): Plastic deformation of wadsleyite: IV Dislocation core modelling based on the PeierlsNabarro-Galerkin model. Acta Mater., 58, 1467-1478.

Miyajima, N. \& Walte, N. (2009): Burgers vector determination in deformed perovskite and post-perovskite of $\mathrm{CalrO}_{3}$ using thickness fringes in weak-beam dark-field images, Ultramicroscopy, 109, 683-692.

Morniroli, J.P. (2004): Large-angle convergent-beam electron diffraction applications to crystal defects, CRC Press, Boca Raton, FL, 376 p.

Morniroli, J.P., Vankieken, D., Winter, L. (1994): Electron Diffraction. Dedicated Software to Kinematicaly Simulate CBED Patterns (USTL, Lille).

Mussi, A., Cordier, P., Frost, D.J. (2012): Crystal defects in dense hydrous magnesium silicate phase $\mathrm{A}$ deformed at high pressure: characterization by transmission electron microscopy, Eur. J. Mineral., 24, 429-438.

Omori, S., Komabayashi, T., Maruyama, S. (2004): Dehydration and earthquakes in the subducting slab: empirical link in intermediate and deep seismic zones. Phys. Earth Planet. Inter., 146, 297-311.

Pacalo, R.E.G. \& Parise, J.B. (1992): Crystals structure of superhydrous B, a hydrous magnesium silicate synthesized at $1400^{\circ} \mathrm{C}$ and 20GPa. Am. Miner., 77, 681-684.

Ringwood, A.E. \& Major, A. (1967): High pressure reconnaissance investigations in system $\mathrm{Mg}_{2} \mathrm{SiO}_{4}-\mathrm{MgO}-\mathrm{H}_{2} \mathrm{O}$. Earth Planet. Sci. Lett., 2, 130-133.

Schmidt, M.W. \& Poli, S. (1998): Experimentally based water budgets for dehydrating slabs and consequences for arc magma generation. Earth Planet. Sci. Lett., 163, 361-379.

Tanaka, M., Ueno, K., Harada, Y. (1980): Large-angle convergent beam electrondiffraction. J. Electron Microsc., 29, 4, 408-412. 
Thurel, E. \& Cordier, P. (2003): Plastic deformation of wadsleyite: I. High-pressure deformation in compression. Phys. Chem. Minerals, 30, 256-266.

Ulmer, P. \& Trommsdorff, V. (1995): Serpentine stability to mantle depths and subduction-related magmatism. Science, 268, 858-861.

Vincent, R. \& Midgley, P.A. (1994): Double conical beam-rocking system for measurement of integrated electron diffraction intensities. Ultramicroscopy, $\mathbf{5 3}$, 271-282.

Voegele, V., Cordier, P., Sautter, V., Sharp, T.G., Lardeaux, J.M., Marques, F.O. (1998): Plastic deformation of silicate garnets II. Deformation microstructures in natural samples. Phys. Earth Planet. Inter., 108, 319-338.

Yamasaki, T. \& Seno, T. (2003): Double seismic zone and dehydration embrittlement of the subducting slab. J. Geophys. Res., 108, 2212. 